\title{
Denn sie wissen nicht, was sie tun ...
}

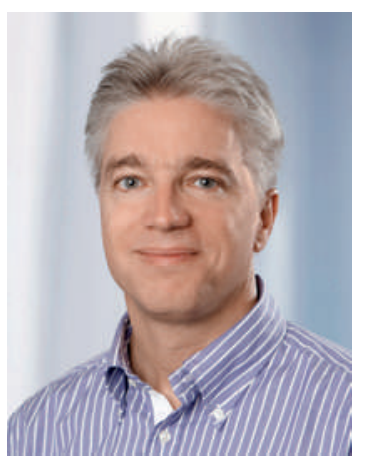

... wenn sie sich in ein solches standespolitisches Amt wählen lassen. Ziemlich genau vor vier Jahren wurde ich von den Delegierten der Ärztekammer in den Zentralvorstand der FMH gewählt. Etwas naiv, mit einer Management-Ausbildung in der Tasche und politischer Erfahrung in der Fachgesellschaft und der fmCh habe ich mich für diese Aufgabe zur Verfügung gestellt und wurde, nach wohlwollenden Eintrittsvoten und als rare Spezies der schneidenden Zunft, im ersten Wahlgang gewählt. Im Vorfeld habe ich versucht, die Freuden und Leiden eines solchen Amtes etwas abzuschätzen, mir ein Bild der Arbeitsbelastung zu machen und das Wohlwollen der Klinikleitung sowie meiner Mitarbeiterinnen und Mitarbeiter abzuholen. Heute, Hunderte von Sitzungsstunden, Tausende von E-Mails und fünf Bypässe später, weiss ich, dass es anders ist, als man gedacht hat. Als klinisch tätiger Arzt ist man gewohnt, im Viertelstundentakt Entscheide zu fällen, die eine sofortige Reaktion auslösen. Der Verbund Arzt-Patient ist überschau- und meistens auch gut steuerbar, und auch das Management des KMU Spital lässt sich fachlich und intellektuell fassen.

\section{«Wenn Du schnell gehen willst, so gehe alleine, wenn Du hingegen weit gehen willst, gehe zusammen.»}

Ganz anders in der Politik. Dort hat das gesprochene Wort die Tendenz, an Verbindlichkeit zu verlieren, scheinbar logische Argumente büssen an Bedeutung ein, und die berühmten Mühlen mahlen so langsam, dass das Mehl madig wird, bevor es zu Brot verarbeitet werden kann. Das hat durchaus auch seinen Reiz. Wenn man einmal die Spielregeln durchschaut und akzeptiert, dann eröffnet sich eine Welt, die man bisher nicht gekannt hat. Man sitzt an einem Tisch mit Protagonisten unterschiedlicher Provenienz und beginnt zu realisieren, dass das Medizinstudium Spuren hinterlassen hat, die manchmal eine gewisse Einengung der Wahrnehmung bewirken können. Eindrücklich versteht man, dass das Gegenüber ebenso fundiert und motiviert eine gegenteilige Meinung vertritt, die näher betrachtet auch eine Logik hat. Man merkt, dass Kompromisse und Lösungen nur möglich sind, wenn sich jeder bemüht, die andere Logik zu begreifen und somit auch zu akzeptieren. Gepaart mit einem gewissen gegenseitigen Vertrauen sind dann auch Fortschritte und Ergebnisse möglich. Dann macht Verhandeln plötzlich Spass und wird zu einer echten Herausforderung. Zudem hat eine gewisse Entschleunigung der Prozesse nicht nur Nachteile. In unserer hektischen Zeit findet man gar keine Musse mehr, Probleme in Ruhe zu überdenken. Rasch und manchmal ohne viel Zeit der Reflexion werden Entscheide gefällt, deren Tragweite und Konsequenzen man erst später entdeckt.

\section{Als Vertreter der FMH in nationalen Gremien lernt man, dass Kompromisse und Lösungen nur möglich sind, wenn sich jeder bemüht die andere Logik zu begreifen und zu akzeptieren.}

Als bekennender Anhänger der kollektiven Intelligenz erkennt man zudem in einer solchen Tätigkeit die tiefere Bedeutung des afrikanischen Sprichwortes: «Wenn Du schnell gehen willst, so gehe alleine, wenn Du hingegen weit gehen willst, gehe zusammen.» Auf diese Weise ist ein gutfunktionierender Zentralvorstand imstande, komplexe Fragestellungen anzugehen und im Kollektiv Lösungsvorschläge zu erarbeiten. Allerdings, der Preis für eine solche Tätigkeit ist nicht zu unterschätzen, die Arbeitsbelastung führt einen manchmal an die Grenzen der eigenen Möglichkeiten.

Ich möchte mich bei allen, mit denen ich in den letzten Jahren zusammenarbeiten durfte, ganz herzlich bedanken sie haben mein Leben bereichert. Bei denjenigen, die sich über mich aufgeregt haben, möchte ich mich entschuldigen, sie mögen es mir nachsehen. Die Tätigkeit im FMH-Zentralvorstand hat mich geprägt, und ich möchte sie nicht missen. Gott sei Dank wusste ich damals nicht, was auf mich zukommen würde.

Dr. med. Daniel Herren, Mitglied des Zentralvorstandes der FMH, Verantwortlicher für das Ressort Daten, Demographie und Qualität 